\title{
LECTURER CONCEPTIONS OF AND APPROACHES TO DECOLONISATION OF CURRICULA IN HIGHER EDUCATION
}

\author{
N. F. Mashiyi* \\ e-mail: mashiyin@cput.ac.za
}

L. Meda*

e-mail: medal@cput.ac.za

\author{
A. Swart* \\ e-mail: swarta@cput.ac.za / http://orcid.org/0000-0001-8693-3124 \\ *Faculty of Education \\ Cape Peninsula University of Technology \\ Mowbray, South Africa
}

\section{ABSTRACT}

This report forms part of a larger project that investigated lecturer and student conceptions of decolonisation and decolonisation of curricula at subject level in a South African higher education institution. The study adopted an interpretive paradigm and an on-line questionnaire was administered to all the lecturers in a Faculty of Education in the Western Cape. A de-colonial perspective was used as a lens to interpret the data. In general, participants viewed decolonisation as a worthwhile project that can contribute to the development of a socially-just post-colonial and post-apartheid society. Consistent with the fact that knowledge is created differently in different subjects, the findings revealed varied conceptions of and approaches to the decolonisation of curricula among academics. The study concludes that decolonisation is a complex and multilayered concept. However. if there are shared understandings of what decolonisation of curricula entails in the different disciplines, and consultative, participatory multi-disciplinary/trans-disciplinary approaches to decolonisation are adopted, significant progress will be made in achieving the goal of decolonising university curricula.

Key words: decolonisation of curricula, varied conceptions, approaches to decolonisation, decolonial perspective, curricula

\section{INTRODUCTION}

Current debates on decolonisation in higher education reveal that in post-colonial and apartheid South Africa, university curricula have not been transformed and remain rooted in colonial, apartheid and Western world views (Heleta 2016; Mheta, Nyanga-Lungu and Govender 2018, 6). These historical and socio-political events have de-valued indigenous ways of knowing and 
"set the grounds for the continued marginalisation of Indigenous students, communities, cultures and histories" (Louie 2017, 16).

Keet (2014) argues that the higher education sector and the disciplines have been complicit in supporting and furthering the colonial project in its focus on epistemic "othering" and "hermeneutical injustice". According to Keet efforts at decolonising knowledge from an African perspective have not succeeded over the past few decades because of the conditions (savoir) of knowledge reformulations and their expressions as disciplines (connoissance). "Only if we view the 'decolonisation of knowledge' as the collective processes by which disciplinary practices are successful in working against the inscribed epistemic injustices of all knowledge formations can we claim for ourselves a commitment towards epistemic justice without delay" (Keet 2014, 35) This view is similar to Waghid's argument $(2002,457)$ that for education transformation to be socially-relevant in South Africa, it should be guided by and allow for the integration of Mode 1 (disciplinary knowledge) and Mode 2 (socially-distributed knowledge) forms of knowledge production which would cause academics to engender community service which integrates their research at universities and its application in the broader community.

Research studies and theoretical positions on decolonisation suggest a focus on structures and iconography; access; large systems of authoritative control; assessment procedures and methods of evaluation and curricula changes (Mbembe 2016). Some have argued for the adoption of indigenous research methods to transform curricula (Chilisa 2017); reframing and reconstructing the curriculum (Keet 2016); a balance between Africanisation and internationalisation (Kamwendo 2016); the adoption of an African philosophy in the Africanisation of higher education to emancipate African people (Msila 2016); and for academics to guard against "indigenous epistemicide" (Shava 2016). Other studies focus mainly on the integration of African epistemologies into existing curricula at school level and take the view that IKS and Science should be viewed as intersecting domains instead of separate domains of knowledge (Taylor and Cameron 2016; Shava 2016). Mheta et al. (2018, 6) investigated what decolonisation might mean to lecturers, students and the community at the Durban University of Technology and concluded that there was no need to be prescriptive on the contentious issue of decolonisation and that their paper only "opens up ways of re-thinking the university curricula and the ways in which it is delivered". This implies that teacher and student roles have to change and a socio-cultural - constructivist perspective adopted in university classrooms to enhance students' knowledge-creation strategies and conceptual understanding. Mheta et al. (2018) were also of the view that some of the suggestions made by participants needed further discussion. In a study in which Du Plooy (2006) explored the 
integration of Africanism in Communication Science she concluded that Africanism should not be treated as an "add-on" and should instead be seen as an integral part of an institution's strategy for post-apartheid and post-merger transformation. Du Plooy posits that academics do not operate in a vacuum and as they strive to "meet equity and efficiency goals", they should consult and collaborate with diverse role players including adult learners.

"Collaboration can therefore serve to promote the development of conceptual skills, including self-reflection, networking to obtain and assimilate information, decision-making, allocation of resources such as skills, time and money, and the initiation of opportunities to develop and change curriculum content. Collaboration and self-assessment can also contribute to the development of role-players as human resources and the promotion of indigenous knowledge systems, including the consolidation of democracy." (Du Plooy 2006, 206).

In line with Du Plooy's emphasis on the importance of collaboration and a protracted consultative process in the decolonisation project, Baron $(2018,326)$ concluded that the adoption of an inclusive and ethical contextual curricula design that uses a cybernetic approach and conversational analysis can promote student participation and engagement, personal responsibility and motivation. Furthermore, new and relevant topics are introduced into the curriculum by students. In Canadian universities, Indigenous scholars are hired in Faculties of Education to integrate indigenous ways of knowing in teacher education courses (Louie et al. 2017, 16).

There is a gap in the literature on how lecturers who are the designers and implementers of curricula understand decolonisation when applied to university curricula and the approaches that could be adopted to decolonise curricula, teach, assess and research in one's field of expertise. In this article the authors argue that when there are shared understandings among discipline experts on what decolonisation should entail and which approaches to adopt in the different disciplines or across disciplines, significant progress will be made in achieving the goal of decolonising university curricula.

\section{PROBLEM STATEMENT AND RESEARCH QUESTIONS}

In recent years, the student movements - Rhodes Must Fall (RMF) and Fees Must Fall (FMF) in the South African higher education landscape have put the decolonisation issue in the spotlight. Although students have been very vocal about what needs to be done in order to transform higher education curricula, not much has been written about Initial Teacher Education lecturers' conceptions of decolonisation, and what approaches and frameworks could be adopted to decolonise higher education curricula. Knight $(2001,369)$ defines curriculum as "a set of purposeful, intended experiences". It may be divided into at least four parts: "content, 
organisation, learning and teaching methods, and assessment". Knight critiques outcomes-led curriculum planning as a poor approach in contexts requiring complex learning (e.g. universities) and argues for the process model of curriculum creation as an alternative. Einsner (1994, 47, in Toohey 1999) defines "curriculum ideologies" as "the value premises from which decisions about practical educational matters are made" and "beliefs about what schools should teach, for what ends, and for what reasons". Beliefs about curriculum are usually tacit and unexamined (Toohey 1999). The current study attempts to address this gap and is underpinned by the following research questions:

1. What are lecturers' conceptions of decolonisation of curricula?

2. What are the suggested approaches to decolonisation of curricula at disciplinary/subject level?

\section{RESEARCH DESIGN}

This qualitative study is located within an interpretive paradigm. Assumptions underpinning interpretive research are that there are multiple realities/truths which are historical, local, specific and not generalizable (Guba and Lincoln 1994, in Bertram and Christiansen 2017, 26). These multiple realities are created through the interpretations of research data in order to "understand human agency, behaviour, attitudes, beliefs and perceptions" (Bertram and Christiansen 2017, 26). A qualitative approach was chosen because the researchers wanted to explore lecturer conceptions of decolonisation and the approaches they thought would be suitable for their subject disciplines, or were already applying in their courses. "Qualitative researchers study things in their natural settings, attempting to make sense of, or interpret, phenomena in terms of the meanings people bring to them" (Creswell and Poth 2016, 7).

The Faculty of Education Ethics Committee granted ethical clearance for the study and informed consent was obtained from participants. An on-line questionnaire comprising mainly open-ended questions was e-mailed to all the lecturers on both campuses of the Faculty of Education. Although there are ethical concerns with online data collection methods participants' privacy, power differentials, ownership of the data, authenticity, and trust in the data collected (James and Busher 2009, cited in Creswell and Poth 2016, 160) they are cost and time-efficient and also provide participants time to think through their responses (Creswell and Poth 2016, 160). Detailed descriptions of data were provided to enhance trustworthiness of the study. Inductive analysis was employed to identify emergent themes from the data.

\section{DECOLONIAL PERSPECTIVE}

Recently, there has been a "conceptual shift" from decolonisation to decoloniality in the 
decolonisation debate. Ndlovu-Gatsheni $(2015,485)$ states that "decoloniality" is not only a long-standing political and epistemological movement aimed at liberation of (ex-)colonised people from global coloniality but also a way of thinking, knowing and doing. Ndlovu-Gatsheni $(2017,77)$ proposes four steps that academics and intellectuals should take in order to achieve epistemic decolonisation. The steps for "doing decolonial change" are:

1. They have to secure Africa as a legitimate epistemic base from which to look at the world;

2. African academics have to shift the geography and biology of knowledge because what masquerades as "global knowledge" has a hegemonic centre which is Europe and North America - that centre has to be moved so as to privilege Africa-centred knowledge;

3. African academics have to invest in "re-thinking thinking itself" as part of launching epistemic disobedience to Eurocentric thinking. They have to fully embrace the idea that all human beings are born into valid, legitimate and functional knowledge systems as part of launching epistemic disobedience;

4. African academics must be true to themselves, accept that they are products of very problematic "westernised" universities and consistently open themselves up to the painstaking but decolonial process of "learning to unlearn" in order to re-learn.

\section{DATA PRESENTATION AND ANALYSIS}

The following themes were identified from the data:

\section{Decolonisation as an inclusive and integrative process aimed at addressing unequal power relations, promoting transformation}

Some of the respondents viewed the decolonisation of curricula as a form of social engineering and transformation through knowledge.

“... from an unequal brutal system divided by race, class, culture, religion, gender to a truly equal, harmonious, non-racial, anti-imperialist society. Colonisation was an intentionally devastating system. To regain our humanity, we must start with ourselves. If not, we are merely paying lip service to decolonisation."

In the same vein, another participant argued that

\footnotetext{
"decolonisation begins in the minds of all participants. It means valuing what we, as Africans and South Africans have to contribute to world knowledge. It is the inclusion of indigenous knowledge, indigenous culture and the ways of our people. In educational circles, it is accepted that we move from the known to the unknown. In our curricula, we need to discover the 'known' of our own people, and not what is imposed on them as a 'should'."
} 
This participant's conceptualisation emphasises the importance of cognitive processes and an inclusive approach to decolonisation of curricula where all modes of knowledge are considered worthy and equal. Another related view was that decolonisation of curricula involves being critical about how knowledge is produced and used. It is about,

\begin{abstract}
"showing respect for all knowledge as the most basic concept that constitutes a social justice curriculum. Our students must understand the role of knowledge in the advancement of societies, but students must also learn how knowledge has been abused for self-gain and the most violent atrocities inflicted on mankind. It is important to be self-critical and not only see knowledge abuse as that of particular people - throughout history there has been an abuse of knowledge by all people. So from a social justice perspective let's develop a critical lens on our own knowledge (and of course the production process) and those of others while being respectful and working together to explore ways of enhancing knowledge for a humane world."
\end{abstract}

This response reveals a deep knowledge of history about how some knowledge was de-valued and dismissed as not valuable, and how this negatively affected the thought-processes (mindsets) of those who were on the receiving end of colonisation. The participant argues for an inclusive curriculum that is underpinned by social justice principles and can promote critical and questioning minds.

\title{
Decolonisation of curricula entails the integration of previously marginalised African epistemologies and languages into university curricula
}

The pervasive view was that the process of decolonising university curricula should foreground the integration of African epistemologies (IKS) into curricula, that is, the inculcation of values, attitudes and beliefs that stand to benefit African people/locals - valuing what Africans and South Africans have to contribute to world epistemologies.

"So, the emphasis should be on the inclusion of all cultural perspectives more, than on decolonisation". "One cannot remove the past, but one can change the future. So, let this rather be an inclusive process that adds to the curriculum and not detracts. This way, all parties will transform and grow. It is a natural process that can be enhanced, but not forced or stopped." A decolonised curriculum should, "take into account the African/South African context and reality and acknowledge the contributions of Africans to all the academic fields such as philosophy, language etc. It is the integration of silenced/unheard voices into education."

The view that a decolonised curriculum should be underpinned by social justice principles was echoed by another participant,

"Decolonisation requires us to be inclusive of other knowledge systems and ways of learning as no knowledge system is superior to another. A decolonised curriculum is one that does not only focus on European knowledge, but studies African knowledge as well, to promote African 
languages to become scientific languages and to ensure mother tongue education - for ALL in our country."

Another participant viewed decolonisation of university curricula and internationalisation as related processes and highlighted inclusity and redress as key principles that should underpin curriculum transformation,

"Decolonisation of the curriculum does not mean teaching students about South African content only. It does not mean shutting down all doors of information with western origins. It simply entails integrating South African and African knowledge into the current curriculum. Our current curriculum is predominantly Western. Thus, our students are orientated to internationalization. We are therefore arguing that in addition to western content that we are teaching our students, we have to bring in African knowledge as well. Thus, internationalization will be attained in the sense that students will be enriched by their indigenous African knowledge as well as Western knowledge. It is pointless to prepare students to be marketable internationally when in actual fact they cannot work in their local or national contexts. We are advocating for an inside-outside approach. Meaning - students learn what is in their country, region, continent (inside) and then abroad (outside). International knowledge can integrate a process of decolonisation as part of a process of globalisation where not only one specific knowledge dominates."

\section{Decolonisation is synonymous with Africanisation of curricula and also entails positioning Africa globally}

Others viewed decolonisation as synonymous with Africanisation and becoming part of the global community

\footnotetext{
"Decolonisation does not imply being isolationist. Africanisation of the curriculum could be one of the consequences of decolonisation. The two concepts do not exclude each other. It is possible to be both. We are part of a global world and therefore it is time for the rest of the world to take note of Africa and South Africa as places of higher learning and academic achievement. It is time to become part of the international community."

"It is about removing bias from (current) curricula, and also about not limiting the intepretation and implementation of curriculum to one lens."
}

The views stated above are consistent with Mgqwashu's (2015) who argues that "decolonisation should be about appreciating difference, not despising it". According to Mgqwashu, "academic decolonisation means creating an environment for my students to receive a holistic educational experience which will ensure intellectual exposure to aspects of life in general that formal disciplinary content may not necessarily offer".

\section{Integration of African philosophical thought into curricula as an expression of identity}

A related but more nuanced response was that 
"decolonisation was about teaching students about what is happening in South Africa, Africa and abroad - teaching students about various relevant African writers, theories, philosophical assumptions and African ideologies like Ubuntu. A decolonized curriculum enables students to learn about their own cultures, identities and what is happening in their environment rather than adhering to western models and theories to guide our knowledge system. This does not mean we have to completely remove western knowledge - no, but integrate African indigenous knowledge into the western curriculum that our students are currently studying. I don't believe that decolonisation means denuding the curriculum of international knowledge. I believe that it is an inter-weaving of indigenous, national and international knowledge, in appropriate and meaningful ways."

\section{ADOPTION OF IKS TO SOLVE CHALLENGES ON THE AFRICAN CONTINENT}

A more critical perspective than the one presented above was that decolonisation can help provide solutions to African challenges. Decolonisation was viewed as

"a philosophical perspective which seeks to address the challenges faced by modern African societies through the use of their IKS instead of Western ideologies which have failed in many cases. In my view, by decolonising the curriculum, universities will be able to inculcate societal values that will benefit local people. As it stands now, the values perpetuated by the existing curriculum benefit colonialists as they are portrayed as heroes or saviours of the majority of the African people. Attitudes and beliefs created among the youth by the existing curriculum mean that they have to look forward to a western type of Africa which may never exist. This places the youth at a disadvantage as what they expect, and what they experience, are not compatible. In fact, the colonised curriculum serves the interest of the rich people as it prepares some people to be dominated. Decolonisation should be about acknowledging the underlying power relations and adapting the curriculum in such a way that these forces are acknowledged in a visible way: allowing access and beneficiating those who participate in it."

\section{VARIED CONCEPTIONS OF DECOLONISATION AND TRANSFORMATION}

There were varied views on whether transformation is the same as decolonisation. One view was that these two terms are related. "Decolonisation cannot happen without transforming Higher Education. The one implies a change in the other and will be a natural evolutionary process which cannot be stopped."

Others regarded transformation and decolonisation as complementary processes. "Universities per se are rather colonised spaces. The call for decolonisation should also address the colonised 'spaces and places' at HE institutions." Other respondents viewed transformation as synonymous with decolonisation, "if social justice is the aim". Another view was that decolonisation is one way of transforming higher education.

"However, it may not be the same as transformation of Higher Education since it has been transformed so many times without decolonising the curriculum. This depends on who transforms. Transformations brought about by the ruling class or western masters are cosmetic changes meant to continue marginalising the already disadvantaged Africans. If the curriculum is decolonised, it removes the barriers. It enables Africans to redefine themselves and their role in the world and 
tries to address outstanding social injustices done by the existing curriculum. You can transform without decolonising the curriculum itself."

Some conceptualised transformation as a separate but related process from decolonisation and that decolonisation is "not part of transforming universities". "Transformation is about access, sustainability and change in higher education. Decolonisation is about integrating African indigenous knowledge systems. The two are different, but closely related in some ways." Another participant also argued that "transforming Higher Education is about student access and success," and achieving equity targets - "getting suitable black candidates to fill strategic positions in an organisation".

For some, although decolonisation has the potential to transform Higher Education, "the call for decolonisation is about alerting stakeholders to the way in which universities are perpetuating the colonial project. So it will transform Higher education." Transformation in Higher education relates to the curriculum and is more

\footnotetext{
"about making sure that all students get a quality education and that buildings and equipment are upgraded to an equal status as others".

"There will be changes and transformations, but I do not think higher education will transform $100 \% . "$

"Decolonising the curriculum is included in transforming higher education."

"It's similar, but not the same. Transforming higher education requires a mind-shift of ALL participants, and black students, particularly, need to start believing that they are the same, and in many cases better, than their peers. A decolonised curriculum is ultimately the responsibility of the university, and should be driven by critical academics. Transforming higher education can be driven by anyone who can think!"
}

\section{VARIED PERSPECTIVES ON WHETHER UNIVERSITY CURRICULA SHOULD BE DECOLONISED OR NOT}

Most of the respondents were of the view that curricula must be decolonised and advanced the following reasons: - to build an anti-imperialist non-racial society; develop students' critical thinking and reflection; promote international understanding and reflection on the past, present and future; help students acknowledge differences in opinions, yet, find ways to understand one another and live in peace despite differences in cultures and histories; develop empathy for difference; expose students to different perspectives on the same knowledge (past, present and future); transform universities; develop students' appreciation for their own African theories and initiatives, and academic contributions; reflect African voices in African university curricula and address the needs of the South African society; promote a sense of belonging and value for students at their own university. 
"I want them to feel that what they are a part of is valued and accepted as formal knowledge. I want them to feel worthy. I don't believe that they can feel this if the information that is imposed on them is way beyond their contexts. How can they value Shakespeare when they have not yet learnt to value Zakes Mda, or people like John Kani?"

Some were of the view that not all the courses can be decolonised. However, others maintained that subjects such as Economics would benefit immensely from decolonisation. One of the lecturers wrote,

"decolonization must take place where it is needed, where it will be beneficial for students, culture, country and university. We must not decolonize because it is asked by some students, but because it is necessary and an integral part of the quality of knowledge and learning."

Another view was that decolonisation is a necessary and worthwhile activity as long as

"it is not part of a political drive. The power relations in society have changed, yet universities and other touchstones of society still function and serve the same segment of society. However, politics and education are intertwined, each influences the other. Colonialism was a political strategy. It is difficult to understand how curriculum as a concept can be apolitical when colonisation and apartheid were underpinned by a philosophy that was aimed at subjugating the black majority in the Africa and providing them an inferior education."

\section{SCEPTICISM AND HOPE ABOUT DECOLONISATION IN THE DIGITAL ERA}

Some lecturers viewed digital technologies as another form of colonisation/enslavement that is reminiscent of the past.

"I feel the digital era another form of colonisation in which African people have embraced technology in which they have little input and it is used to divert their thinking to something else. We are no(t) little children originally crying for milk, but guess what, the mother outwits us and gives toys to play with and forgets what we were crying for. By the time we realise that we have been cheated something new to divert our attention is in place. Instead, digital era should enable us to explore various means by which we can decolonise - as we have better means of communication - doing things such as learning and research. Digital era provides us with the opportunity to share our knowledge and also advance by exploiting what is good from the existing system and blending it with what we already practise in our cultures."

Another view was that technologies present an opportunity for fast tracking the decolonisation process:

"There is no turning back the clock. Whilst the technological advances sadly do not improve the lot of the disadvantaged millions, an emphasis on decolonization might help to use digital to the advantage of the suffering masses."

One lecturer felt that technology had added a positive spin to the calls for decolonisation and that all forms of knowledge can fit into the digital era. 
"The digital age has made it difficult to marginalise voices. I cannot see why the digital era will be a problem. We do not get rid of modernization because we are decolonizing! There is a huge difference. Decolonization does not mean that we get rid of modern ways of life."

Another maintained that technology can be used to advance the decolonisation process.

\section{VARIED APPROACHES TO DECOLONISATION OF CURRICULA}

Lecturers held different views about approaches to the decolonisation of curricula. Some felt that it was important to establish a common understanding about why curricula should be decolonised, "Is it to change a system fundamentally or purely because it is the academic flavour of the day - a topic that has currency, something to use for research purposes with no real change in sight?" Other issues to consider would be the institutional ethos and approaches to teaching. Others proposed engagement between students and staff on debates about the decolonisation of curriculum. Saurombe $(2018,119)$ suggests factoring in archives as "centres of critical inquiry" in the decolonisation of higher education curricula.

All the participants were of the view that the process of decolonisation of curricula should be intense, inclusive and participatory, involve all stakeholders at the university - students and academic staff. There was also the view that currently, "the concept of decolonisation has a racial and political meaning". Another respondent argued for an eclectic approach to curriculum reform.

The following were identified as strategies that faculties could use to inform the decolonisation process: engagement in research with local and international partners, conducting participatory workshops on decolonisation and adopting a research-based approach to curriculum reform. "Curriculum reform should be informed by Critical Theory. A lot has been written about our history and some of the stuff in the public domain is biased/does not reflect the contribution of all the role-players to our painful and tragic past". Authentic sources should be used in order to give a balanced view of events. The process of integrating all this information into curricula can then follow. Another recommended Design-based Research as a tool for curriculum transformation.

A bottom-up approach would have to be adopted and current curricula "evaluated to check for bias and narrowness". A study of what (content knowledge) is presently available would have to be conducted and content analysis done to determine its effect on society. Depending on the findings, some of the content would have to be replaced or retained. Benchmarking content with what is offered in other institutions locally and internationally and arranging consultations with subject specialists, students and the Department of Basic Education (DBE) 
would carry the process forward.One lecturer viewed this exercise as a continuous, evolving and rigorous process.

"I believe that we should form a faculty-based group who will lead the way. Regular meetings should occur with staff, in which the value of the process is carefully explained. A staff mentor should be appointed for each subject. The current curriculum should be carefully evaluated to assess whether it is possible to adapt it or whether it needs to change completely."

For most of the participants, curriculum change should be driven below and lecturers' agency was viewed as critical for the success of the decolonisation project. Some lecturers re-wrote curricula and implemented peer assessment. Indigenous ways of knowing were also integrated into curricula. One lecturer "discouraged Western stereotyping" and promoted "indigenous methods that are common among indigenous people" of South Africa.Others had started consulting with colleagues to unpack the concept and how it can be implemented at subject level.

"This is a new process, which starts with discussions with colleagues, students and community. It needs to be approached in an empathetic and sensitive manner so as to ensure all parties buy into this concept. This is still in a planning phase and will only be implemented at a later stage. But for now, we are revisiting choices of prescribed literary works and doing research in the field."

Students engaged in a variety of authentic teaching-learning activities in some courses, e.g. teaching students about African knowledge systems and western theories and showing them how African theories can be used to explain the same phenomenon, e.g. teaching the Social Model of Inclusive Education and Ubuntu in Africa. Students analysed papers written by African writers, critiqued and evaluated the knowledge against what happens in other western contexts.Some lecturers adopted multilingual pedagogy during lectures and used historical interrogation to unpack subject content. One lecturer also

"works towards developing a social justice curriculum and explores the production of knowledge across the world. A service learning course was also designed in which my students are grappling with the notion of funds of knowledge in which their lived experiences and those of others inform their practice."

The lecturer above has created a learner-centred space for her students where peer-learning and open communication are valued. The lecturer made sure that

"content taught is relevant to the context in which we find ourselves and the importance of social justice with regard to issues of poverty and other social barriers to learning is emphasised. Students go out to schools weekly and engage with learners in learning support."

Self-empowerment through extensive reading on the topic was one of the ways in which the 
lecturer tried to make sense of the concept,

"I am talking about decolonisation in all my subjects and I discuss the topic with a lot of people. At this stage I've made a bibliography on the topic - colonisation and decolonisation - and I am busy reading a lot about it."

Some of the newspaper and journal articles used by one of the lecturers for teaching Academic Literacy focused on decolonisation and transformation in higher education. Others were uncertain about how to decolonise curricula and only included works by African writers in their courses.Another lecturer included examples of international artists, but also balanced these by showing the same elements in the work of local artists.

"I wrote the national visual Art curriculum for grades 1 to 9, and in this document, there are many examples of local arts and crafts. Some practical projects draw inspiration from African artists and crafters, for example, Willie Bester, Muafangejo, Gerard Sekoto, etc. In my classes, we look at South African Resistance Art, African body adornment, African masks and their significance, etc."

Most of the participants mentioned the importance of extensive and intensive reading of texts to help all stakeholders make sense of the decolonisation process. "I must engage my students to explore the topic with me and read as much as possible and to make up their own minds.Workshops on decolonisation should be organised to start discussions and foster partnerships and collaboration among stakeholders."

One of the lecturers highlighted the importance of teaching African theories and referring to African authors and thereby showing the relationship between western theories and African ideologies of Ubuntu. Students could develop podcasts of inclusive Education in their communities and schools and compare those with Western and African theories. The lecturer argued that multilingualism and a wider scope in prescribed literature would broaden the knowledge about cultures.

A disciplinary approach to history teaching was also suggested. "This will ensure that regardless of the dominant 'ism' the purpose of teaching history remains the development of an historical gaze." Ndlovu (2013) argues that "a decolonised historical narrative can possibly lead to the emergence of a cohesive South African national identity".

A stand-alone module on decolonisation was preferred by others. "What is missing from our curriculum is a separate course that runs across the programme - Maths and Society, in which they come to understand that Mathematics is not neutral. Mathematics is deeply political." However, another lecturer was of the view that integration of the topic into subject content was the way to go. "I am integrating decolonisation into my work, especially literature, and I plan to write a whole module about the topic in my literature curriculum, for example 
exploring the theme in Afrikaans literature addressing this phenomenon."

Another lecturer was of the view that the dismal performance of students in Mathematics in comparison to the rest of the world needed to be addressed urgently before there can be discussions about decolonisation in the subject. The lecturer's view was that decolonisation did not apply very much in Mathematics.

\title{
DECOLONISATION OF CURRICULA AND INTERNATIONALISATION ARE COMPATIBLE PROCESSES
}

Although most of the respondents expressed the view that they supported globalisation/ internationalisation, some were uncritical about knowledge from the global North. The dominant view among respondents was that no knowledge is more privileged than others and that the process of decolonisation should be a consultative one - nationally and internationally.

"Internationalization and decolonization need not be mutually exclusive. International Competences (ICOMs) can be harnessed to address decolonization. We started with it at the 2017 International Student Conference in the Faculty of Education.” Another view was that epistemologies, irrespective of their origin need to be interrogated and evaluated, and not taken at face value.

"Globalised content and knowledge systems need to be critiqued by including perspectives from different backgrounds, contexts and cultures and reflecting on all, to discover one's own truth and understanding, creating empathy and respecting differences, while simultaneously recognising similarities. Only as one entity of the human race, can we ensure the future of this planet."

Another argued that

\begin{abstract}
"being international does not stop one from returning to one's values and beliefs. Being international only serves the interest of very few privileged people. I think by decolonising the curriculum we are more likely to be more international than what it is now. We will be able to generate new knowledge based on what we aspire to be and contribute to the world in different ways rather than sticking to the existing norms and standards of a developed world. One must look at other countries who applied decolonisation and whether it worked for them or not."
\end{abstract}

Some lecturers embedded decolonisation as a discussion topic in $2 \mathrm{nd}$, 3rd and 4th year classes. Student exchange programmes between the university, Belgian and Dutch universities also exposed students to other cultures. Exchange students were invited to workshops on decolonisation and theatre that introduced them to seminal African writers such as Ngugi wa Thiongo. Another view was that learning is a social practice and that knowledge that students and lecturers (cultural and social capital) bring into the classroom should be valued. 


\section{DISCUSSION}

In the following section, the themes are discussed in relation to the decolonial perspective and the literature. The study revealed that "decolonisation" is not a neutral or apolitical concept and that lecturer conceptions of decolonisation are influenced by dominant political thoughts and curriculum ideologies. For example, a thread that runs through lecturers' conceptions of decolonisation is the theme of social justice and its under-pinning values - redress,equity, nonracialism equality and inclusivity. These are dominant political ideologies that drive policy implementation in post-apartheid South Africa.

Higher education is synonymous with the creation of new knowledge through complex learning in the various disciplines. The varied conceptions of and approaches to decolonisation of curriculum - also reveal the complexities, multiple perspectives, similarities and contradictions that are typical of higher education learning and teaching. Whilst some lecturers adopted a critical stance about decolonisation and the role of technology, others viewed the integration of other epistemologies as a panacea for everything. There was scant reference to the processes of gathering that knowledge, evaluating, and comparing it to other knowledge forms. Ndlovu-Gatsheni $(2017,43)$ proposes "securing Africa as a legitimate epistemic base from which to look at the world". This means valuing and affirming African ways of knowing and doing and also realising that knowledge is interrelated. Lecturers' responses revealed an acute awareness of this.

Some of the responses foregrounded the role of language in the decolonisation debate. This view is consistent with Mbembe's 2015 argument that the African university of the future will be multilingual. One can argue that lecturers' views on the language issue are based on the understanding that there is a relationship between language and thought and that the use of one's language in high domains such as education can help affirm one's identity and enhance learning. Also, academics were acutely aware of the fact that they cannot afford to uncritically accept other knowledges that are Euro-centric and hegemonic whilst rejecting home-brewed knowledge that has the potential to disrupt learning and contribute to the country's socioeconomic development. Thus, for most of the respondents, "epistemic disobedience" is a necessary condition for the success of the decolonisation project. They see themselves as change agents who should work collaboratively with other stakeholders to "privilege Africancentred knowledge" (Ndlovu-Gatsheni 2017). Decolonised curricula can promote critical thinking and reflection on the past and present, and develop a sense of belonging.

Most of the participants viewed decolonisation as an emancipatory process that could bring about meaningful change to society. They argued that it should be consultative, participatory and inclusive. Some were of the view that decolonisation of curricula should be 
underpinned by research and a social justice perspective and should be initiated from below and driven by a critical mass of academics who will lead the curriculum renewal and evaluation process at faculty level to "purge curricula of myopic views and bias". The intersection between lecturers' personal experiences and professional lives emerged clearly from their choice of words. For some, delivering a transformed curriculum would be a deeply personal and liberating experience.

Most of the participants made concerted efforts to find ways in which they can integrate "other forms of knowledge" into their disciplines, read widely on the topic and consulted with their peers. However, others were either not convinced that decolonising their subjects was possible, or felt that other pressing matters such as high failure rates in higher education should receive priority. Most of the current cadre of academics in South African universities went through an unequal, divisive and racially divided education system. Calls by Ndlovu-Gatsheni that academics should "open themselves up to the painstaking but decolonial process of 'learning to unlearn' in order to re-learn” should not go unheeded.

\section{IMPLICATIONS}

In this article, the authors explored lecturer conceptions of decolonisation of curriculum and their approaches to decolonisation in their disciplines. The study revealed varied conceptions of and approaches to decolonisation. This could be attributed to personal experiences, curriculum ideologies, beliefs about change, professional background, encounters with innovation and curriculum change and fear of the unknown.

The two interesting but unexpected findings that emanated from the study were: the view that not every subject can be decolonised and that lecturers who teach the same subjects may hold different views on how to implement decolonisation in their subjects. The second one was that Eurocentric knowledge should be replaced with IKS. The two findings suggest that there is a need to tread carefully when introducing epistemic changes at programme/degree/diploma level and that whatever approaches are agreed upon by the subject specialists, the following requirements should be met:

1. There is consultation and shared understanding about what decolonisation of curricula entails, why and how it could be done, by whom and for what purpose.

2. There is a deeper understanding of the denuding role of colonialism and coloniality (neoliberalism) and how these processes have affected the lives, minds and psyche of the (ex-) colonised.

3. There is agreement about the inter-relatedness of knowledge (whether African or Western 
in origin) and the need for Africans to take their place in the Global Village.

4. A socio-cultural constructive perspective seems to offer ideal conditions for students, lecturers and community stakeholders to use their experiences and existing knowledge, work in teams, engage in active learning, learn by doing, construct knowledge and solve complex societal/real-world problems. Instead of working in silos, academics could achieve most or all of the above by adopting inter-disciplinary and trans-disciplinary approaches.

In conclusion, although the findings of this study cannot be generalised to other (university) contexts, what comes out strongly from the data is that decolonisation at subject level is possible as demonstrated by the varied ways in which lecturers in this study introduced new content in their disciplines and sometimes substituted Western theories and models with African ways of knowing. An inclusive, collaborative and participatory process could ensure the success of the decolonisation project in higher education. This process should be accompanied by a critical re-examination of lecturers' and student roles in the teaching-learning environment.

\section{REFERENCES}

Baron, P. 2018. Ethical inclusive curricula design: Conversational teaching and learning. South African Journal of Higher Education 32(6): 326-350.

Bertram, C. and I. Christiansen. 2017. Understanding research: An introduction to reading research. Pretoria: Van Schaik.

Chilisa, B. 2017. Decolonising transdisciplinary research approaches: An African perspective for enhancing knowledge integration in sustainability science. Sustainability Science 12(5): 813-827.

Creswell, J. W. and C. N. Poth. 2016. Qualitative inquiry and research design: Choosing among five approaches. Los Angeles: Sage.

Du Plooy, G. 2006. Towards African communication science curricula: Challenges for education. COMMUNICATIO 32(2): 189-209.

Heleta, S. 2016. Decolonisation of higher education: Dismantling epistemic violence and Eurocentrism in South Africa. Transformation in Higher Education 1(1): a9. http//dx.doi.org/10.4102/the.v1i9

Kamwendo, G. H. 2016. Unpacking Africanisation of higher education curricula: Towards a framework. In Africanising the curriculum: Indigenous perspectives and theories, ed. V. Msila and T. Gumbo, 17-31. SUN Press: Stellenbosch.

Keet, A. 2014. Epistemic "othering" and the decolonisation of knowledge. Africa Insight 44(1): 23-37.

Keet, A. 2016. Decolonisation of higher education: Dismantling epistemic violence and Eurocentrism in South Africa. Transformation in Higher Education 1(1): 1-8.

Knight, P. T. 2001. Complexity and curriculum: A process approach to curriculum-making. Teaching in Higher Education 6(3): 369-381.

Louie, D., Y. Pratt, A. Hanson and J. Ottman. 2017. Applying indigenizing principles of decolonising methodologies in university classrooms. Canadian Journal of Higher Education 47(3): 16-33.

Mbembe, A. 2015. Decolonising knowledge and the question of the archive. wiser.wits.ac.za (spoken text). 
Mbembe, A. 2016. Decolonising the university: New Directions. Arts and Humanities in Higher Education 15(1). https://doi.org/10.1177/1474022215618513

Mgqwashu, E. 2015. Decolonisation should be about appreciating difference, not despising it. The Conversation. https://theconversation.com/decolonisation-should-be-about-appreciatingdifference-not-despising-it.

Mheta, G., B. Nyanga-Lungu and T. Govender. 2018. Decolonisation of the curriculum: A case study of the Durban University of Technology in South Africa. South African Journal of Education 38(4): $1-7$.

Msila, V. 2016. Africanisation of education and the search for relevance and context. In Africanising the curriculum: Indigenous perspectives and theories, ed. V. Msila and T. Gumbo, 57-69. SUN PRESS: Stellenbosch.

Ndlovu-Gatsheni, S. 2015. Decoloniality as the future of Africa. History Campus: 485-496.

Ndlovu-Gatsheni, S. 2017. The emergence and trajectories of struggles for an "African University": The case of unfinished business of African epistemic decolonisation. http://dx.doi.org/1017159/23099585/2017/V43a4

Ndlovu, M. 2013. Mobilising history for nation-building in South Africa: A decolonial perspective. Yesterday and Today, 9 July 2013: 1-12.

Saurombe, N. 2018. Decolonising higher education curricula in South Africa: Factoring in archives through public programming initiatives. Arch Science 18: 119-141.

Shava, S. 2016. The application/role of indigenous knowledges in transforming the formal education curriculum. In Africanising the curriculum: Indigenous perspectives and theories, ed. V. Msila and T. Gumbo, 121-139. SUN PRESS: Stellenbosch.

Taylor, D. and A. Cameron. 2016. Valuing IKS in successive South African physical sciences curricula. African Journal of Research in Mathematics, Science and Technology Education 20(1): 35-44.

Toohey, S. 1999. Designing courses for higher education. SRHE \& Open University Press: Buckingham.

Waghid, Y. 2002. Knowledge production and higher education transformation in South Africa: Towards reflexivity in university teaching, research and community service. Higher Education 43: 457488. 